\title{
DA ESTÉTICA DA REENTRÂNCIA À ESTÉTICA DA ELASTICIDADE: A ARQUITETURA VERTICAL RESIDENCIAL EM RECIFE, 1960-2010
}

\author{
DE LA ESTÉTICA DE LOS HUECOS A LA ESTÉTICA DE LA ELASTICIDAD: LA ARQUITECTURA \\ VERTICAL RESIDENCIAL EN RECIFE, 1960-2010
}

\author{
FROM THE AESTHETICS OF RECESSES TO THE AESTHETICS OF ELASTICITY: THE VERTICAL \\ RESIDENCIAL ARCHITECTURE IN RECIFE, 1960-2010
}

\section{MOTTA, ENIO LAPROVITERA DA}

\author{
Doutor, UFPE, eniolaprovitera@uol.com.br
}

\section{RESUMO}

Ao analisarmos o último meio século da produção da arquitetura vertical residencial recifense, constatamos uma importante transformação na cultura arquitetônica local, que pode ser sintetizada através da identificação de três momentos: a estética da reentrância, a estética da "fantasmagoria" e a estética da elasticidade. Esses três períodos da produção arquitetônica, longe de se distinguirem por meros aspectos formais, expressam importantes transformações na forma de pensar e fazer o objeto arquitetônico, ao ponto de questionar o que podemos chamar de tradição arquitetônica local - 0 que inclui tanto a prática arquitetônica como a maneira de pensar e ensinar projeto nas escolas de arquitetura.

Conforme veremos, essas transformações não resultam, unicamente, de decisões internas ao campo da arquitetura, mas se articulam e respondem a solicitações econômicas, sociais e tecnológicas, e, via de regra, justamente por, em alguns momentos, questionarem a tradição arquitetônica e provocarem uma importante alteração urbanística na paisagem da cidade, trazem algum tipo de mal-estar aos que parecem ser seus principais protagonistas: os arquitetos.

Por fim, e com base nas respostas que os próprios arquitetos dão as transformações estéticas dos edifícios e, principalmente, pela constatação da emergência de uma nova sensibilidade urbana, pergunta-se: já podemos anunciar uma nova fase na história da arquitetura recifense que poderia ser chamada de "estética da arquitetura urbana ou estética da cidade"?

PALAVRAS-CHAVE: projeto de arquitetura; estética arquitetônica; história da profissão.

\section{RESUMEN}

Al analizar el último medio siglo de la producción de la arquitectura vertical residencial de la ciudad de Recife, constatamos una importante transformación en la cultura arquitectónica local, que puede ser sintetizada a través de la identificación de tres momentos: la estética de los huecos, la estética de la "fantasmagoría" y la estética de la elasticidad.

Esos tres periodos de la producción arquitectónica, lejos de distinguirse por simples aspectos formales, expresan profundas transformaciones en la forma de pensar y de hacer el objeto arquitectónico, al punto de cuestionar lo que podemos llamar tradición arquitectónica local - que incluye tanto la práctica arquitectónica como la manera de pensar y de enseñar proyecto en las escuelas de arquitectura.

Como veremos, esas transformaciones no provienen únicamente de decisiones internas al campo da arquitectura, sino que se articulan y responden a demandas económicas, sociales y tecnológicas, y en general, justamente por cuestionar en algunos momentos la tradición arquitectónica y provocar una importante alteración urbanística en el paisaje de la ciudad, traen algún tipo de malestar a los que parecen ser sus principales protagonistas: los arquitectos.

Por fin, y con base en las respuestas que los propios arquitectos dan a las transformaciones estéticas de los edificios, y principalmente, por la constatación de la emergencia de una nueva sensibilidad urbana, se pregunta: ¿ya podemos anunciar una nueva fase en la historia de la arquitectura recifense que podrá ser llamada "estética de la arquitectura urbana o estética de la ciudad"?

PALAVRAS-CLAVES: proyecto de arquitectura; estética arquitectónica; historia de la profesión.

\section{ABSTRACT}

When analyzing the past fifty years of residential vertical architecture in Recife, we find a significant transformation in the local architectural culture. We can sum it up through the identification of three moments: aesthetics of recesses, aesthetics of phantasmagoria and aesthetics of elasticity.

These three periods of architectural production, far from being distinguished by mere formal aspects, express deep changes in the way of thinking and making the architectural object, to the point of questioning what we could call local architectural tradition - including architectural practice and also the way projects are thought of and taught in architecture schools.

We will show that these transformations are not solely the result of internal decisions to the field of architecture, but they join together and respond to social, economic and technological demands, and, as a rule, precisely because at times they question the architectural tradition and cause a substantial urban modification in the city's landscape, they bring some sort of uneasiness to those that seem to be their main players: the architects.

At last and based on the answers that architects themselves give to the aesthetic transformations of buildings, and above all, due to evidence of the emergence of a new urban sensibility, the question to be asked is whether we can already announce a new era in the history of the architecture in Recife that would be called "aesthetics of urban architecture or aesthetics of the city"?

KEYWORDS: architectural project; architectural aesthetics; history of the profession. 


\section{INTRODUÇÃO}

A produção arquitetônica recifense sobre os edifícios residenciais verticais pode ser sintetizada através da identificação de três momentos: a estética da reentrância, a estética da "fantasmagoria" e a estética da elasticidade.

O texto busca demostrar que a estética dos edifícios longe de se distinguirem por meros aspectos formais, expressam mudanças na forma de conceber e construir o objeto arquitetônico. Conforme veremos, essas transformações não resultam, unicamente, de decisões internas ao campo da arquitetura, mas se articulam e respondem a solicitações econômicas, sociais e tecnológicas, e, via de regra, justamente por, em alguns momentos, questionarem a tradição arquitetônica e provocarem uma importante alteração urbanística na paisagem da cidade, podem redefinir a imagem que a sociedade faz da profissão de arquiteto.

De início, cabe deixar claro que as obras escolhidas não resultam de uma escolha baseada em critérios de qualidade estética, pois foram selecionadas tão somente por expressarem um determinado espírito de época - ou período -, que aqui estamos chamando de "estética". A "estética" é entendida aqui como o resultado do conjunto de conhecimentos e decisões tomadas pelos arquitetos no que se refere à definição da estrutura, programa arquitetônico e soluções plásticas do edifício e que, via de regra, para além de traços autorais, conferem uma certa identidade ou historicidade à forma da arquitetura.

Por essas razões, preferimos não identificar as obras pelos autores, pois o objetivo é mostrar que independente de traços identitários de cada escritório ou autor - elas expressam condicionantes coletivos de um determinado período histórico.

\section{DESENVOLVIMENTO}

\section{A estética da reentrância}

A primeira fase da produção da arquitetura vertical recifense caracteriza-se por uma grande liberdade projetual, tanto no uso dos materiais como na maneira de definir a forma dos volumes edificados. De maneira esquemática, podemos dizer que o resultado estético alcançado resulta de dois gestos fundamentais: a aplicação de reentrâncias e/ou saliências num dado volume prismático originário. É por essa razão que denominamos esta fase como sendo a da estética da reentrância.

Essa fase - compreendida entre as décadas de 1960 e 1970 - coincide com o período de consolidação da arquitetura recifense e se desenvolve num ambiente de forte crescimento econômico e urbano, em que se destaca a arquitetura vertical de edifícios de uso multifamiliar.

A sede de criatividade do arquiteto encontra amparo, então, nas altas taxas de crescimento econômico e, também, na demanda social dirigida aos arquitetos no sentido de contribuírem para a renovação do gosto ou da imagem cultural brasileira, na qual se incluem, a arquitetura e a cidade ${ }^{1}$.

Essa coincidência de oportunidades confere ao arquiteto uma grande liberdade projetual, expressa em volumes de grande variedade formal e que se utilizam de grandes áreas de balanço (saques) e de recortes.

O campo da composição arquitetônica encontra, nesse período, um repertório quase infinito de variações formais, até então livre das restrições econômicas e técnicas que lhe serão impostas pelos construtores nos anos seguintes. Além do que, neste momento inaugural da arquitetura, ocorre uma forte sintonia como essa arte é pensada no campo da prática e no campo do ensino da arquitetura.

Não é por outra razão que, nessa época, mais precisamente a partir da reforma do ensino de $1963^{2}$, se consolidam disciplinas de composição arquitetônica - denominadas de Plástica 1 e 2 -, cujo raciocínio compositivo repete, exatamente, o que estava acontecendo no campo da prática profissional: a partir de um volume prismático originário (prisma, cubo, esfera, dentre outros) em argila, aplicam-se reentrâncias e saliências até se atingir a composição formal desejada ${ }^{3}$. 
Figura 1: Edifício Mirage, Rua dos Navegantes,1617, Boa Viagem, Recife-PE

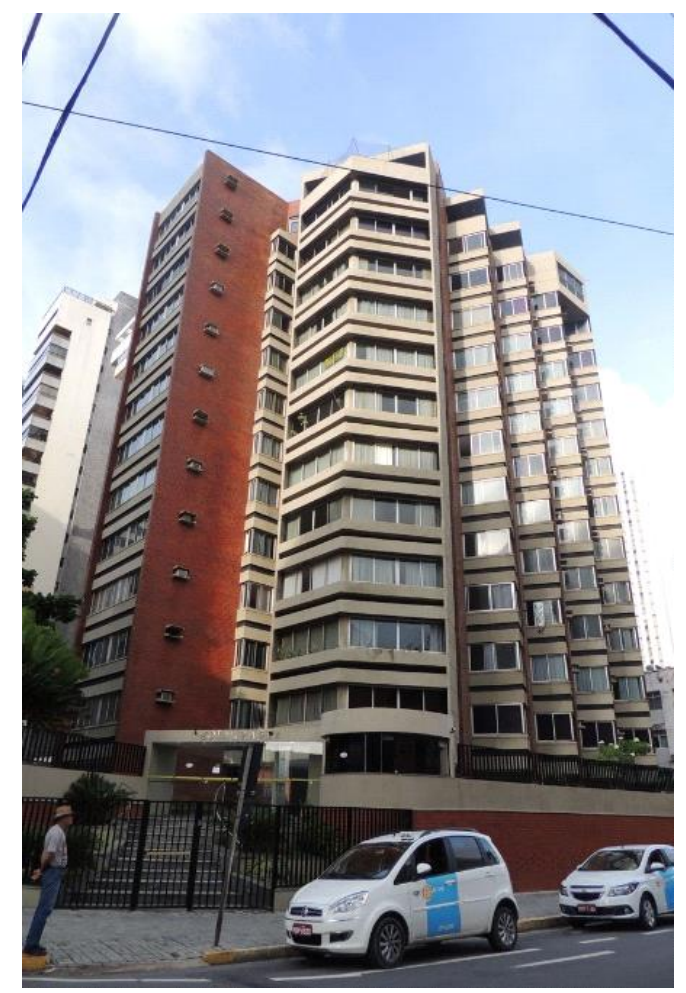

Fonte: Foto do autor

Essa nova estética, posto que nascida na atmosfera do modernismo arquitetônico, vai se firmar através da criação de distinções formais para com os estilos históricos precedentes em que a operação ou gesto projetual da reentrância e saliência ocupará uma posição estratégica. É através desses mecanismos compositivos que se substitui o tratamento decorativo de superfícies por volumes em relevo valorizados pelo jogo de luz e sombra das reentrâncias. $O$ incômodo com o tratamento decorativo das superfícies - característico dos estilos históricos - é tão forte, que, entre os arquitetos modernos, não se pode conceber uma mudança de material ou de cor nas fachadas sem que isso implique numa mudança de plano: daí, mais uma vez, a utilidade do uso do "saque" ou da "reentrância".

Figura 2: Edifício Vila Cristina, Av. Rosa e Silva, 197, Graças, Recife-PE

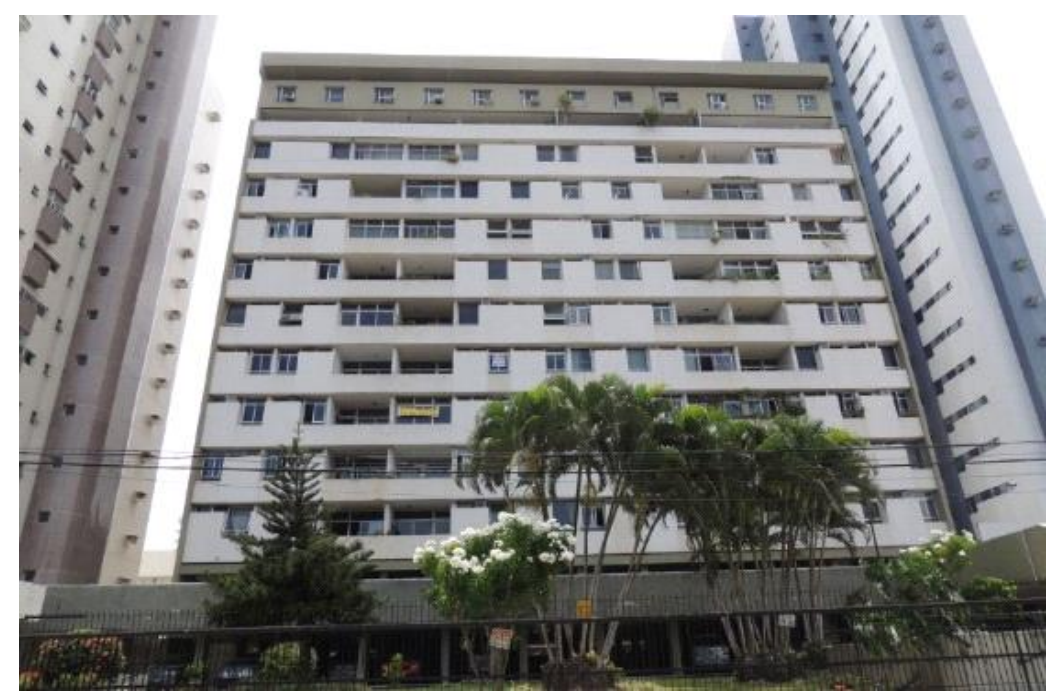

Fonte: Foto do autor 
Estabelece-se, assim, no campo da prática profissional e no do ensino, um conjunto de procedimentos e regras formais à disposição do arquiteto, consolidando assim uma nova tradição - no caso, modernista - de composição arquitetônica.

As qualidades da produção dos edifícios verticais desse período vão reforçar a imagem do arquiteto enquanto agente renovador da paisagem cultural e urbana da cidade. Valoriza-se a busca de soluções formais originais, valendo-se para isso do uso de detalhes construtivos únicos e específicos para cada projeto. A palavra de ordem é, pois, invenção e experimentação formal, e não, tal como se verá mais adiante, padronização e modelo standard.

O protagonismo do arquiteto não ocorre, unicamente, no campo das soluções formais, pois, nesse período, a incipiente indústria da construção civil abre espaço para que o arquiteto contribua para a busca de novas soluções técnicas de construção, de forma a torná-lo coordenador do canteiro de obras e a incentivá-lo a pensar novos programas arquitetônicos.

Isso demostra que o vanguardismo dos arquitetos não ocorre apenas no plano da forma arquitetônica e da inovação técnica, mas também no plano da renovação social das formas de morar e viver na cidade!

Temos, assim, uma geração de arquitetos cujo pensamento e prática profissional consolidam um ethos profissional em concordância com os valores históricos da profissão: o do artista livre criador de formas, mestre do canteiro de obras e, também, educador e criador de novas práticas sociais.

\section{A estética da "fantasmagoria"}

A partir das décadas de 1980 e 1990 do século passado, a produção arquitetônica recifense passa por um forte processo de racionalização e padronização, fato que altera sobremaneira a imagem que a sociedade fazia da nossa arquitetura e do papel social do arquiteto.

Assim, se na fase anterior afirmamos que a busca por uma solução plástica original justificava a busca por novas soluções técnicas, agora, a estética estará totalmente subsumida à técnica e às determinações econômicas. Essa situação é ainda mais enfatizada pela drástica redução do crescimento econômico e - no nível da lógica interna das empresas construtoras - pela existência de uma forte concorrência entre as organizações, fato que as levaram a reduzir custos operacionais.

Figura 3: Edifício Alameda Prince, Rua José Aderval Chaves, 230, Boa Viagem, Recife-PE

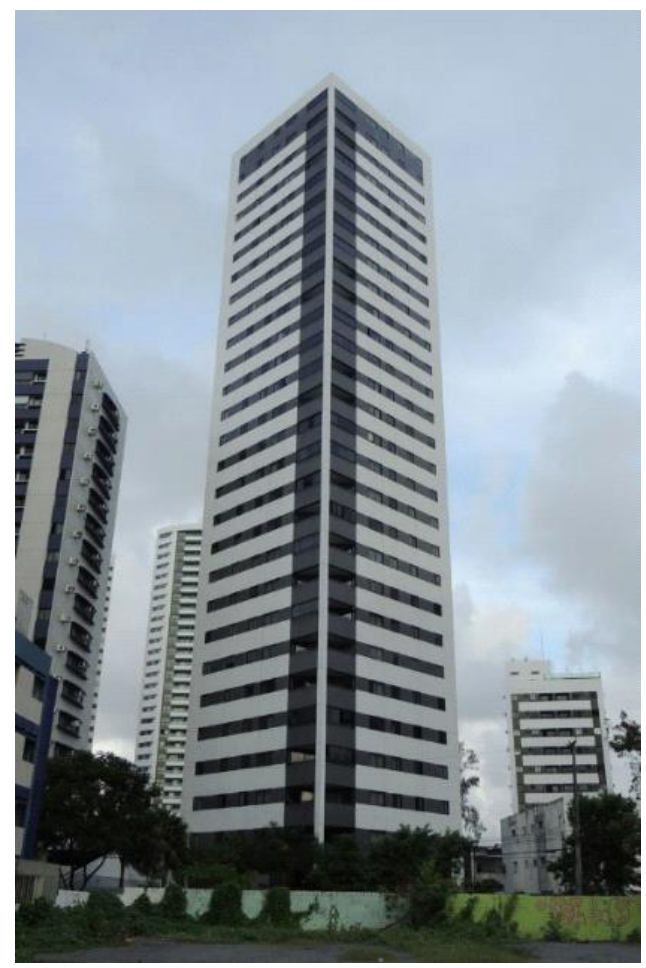

Fonte: Foto do autor 
A consequência visível dessas novas determinações econômicas - e, consequentemente, técnicas - será a progressiva substituição da estética da reentrância por algo que, externamente, e a uma certa distância do objeto arquitetônico, possa parecer com os antigos saques e reentrâncias, sem ser, no entanto, exatamente o objeto originário que ora é referenciado. Essa é a lógica compositiva que estamos chamando de estética da fantasmagoria ${ }^{4}$. Trata-se da estética do que parece (saque e reentrância), mas não é! Na verdade, trata-se de mera pintura ou grafismo compositivo com cerâmicas de cores diferentes, no qual o claro-escuro se destaca, justamente, por tentar trazer de volta um jogo de planos e de profundidade perdidos!

É visível, portanto, uma clara subversão da gramática compositiva da estética da reentrância - e, portanto, da tradição compositiva modernista -, pois agora passa a ser "permitida" a mudança de material ou de cores num mesmo plano ou superfície do edifício! Estamos, de certa forma, de volta ao trabalho compositivo sobre uma mesma superfície, atitude esta que os arquitetos modernistas tanto combateram!

Figura 4: Edifício St. Jaques e St. Thomas, Av. Visconde de Jequitinhonha, 2390 e 2392, Setúbal, Recife.

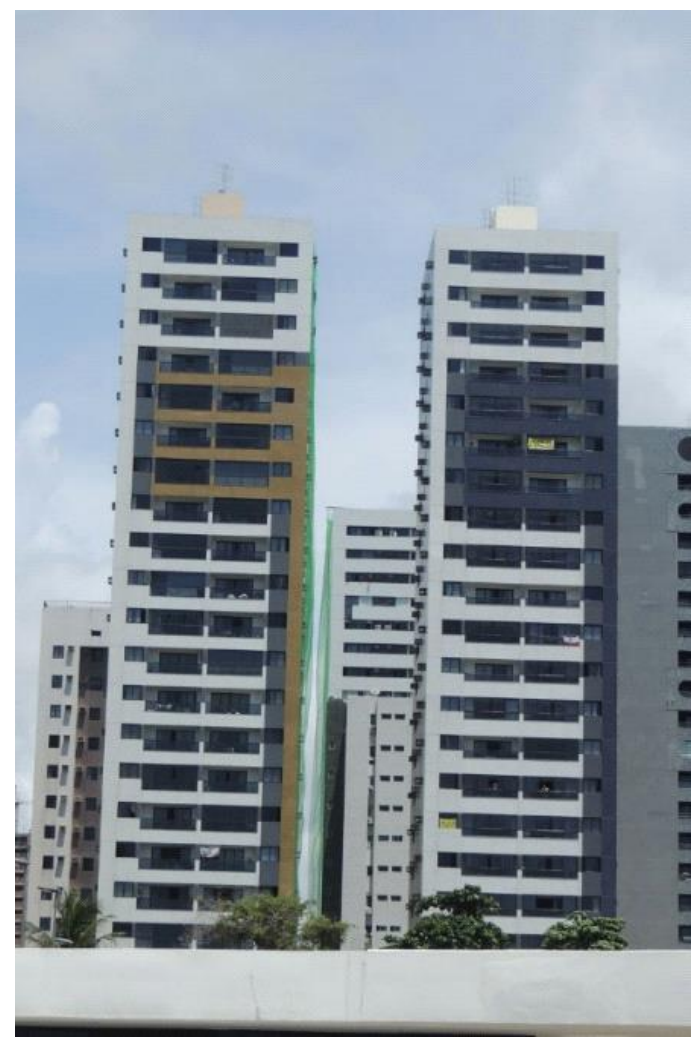

Fonte: Foto do autor

Mas terá sido isso o resultado de uma escolha livre e deliberada dos arquitetos?

Na verdade, a partir da década de 1990, as construtoras, impulsionadas pela concorrência entre empresas e pelos movimentos de defesa do consumidor ${ }^{5}$, passam por um processo de racionalização de atividades, consolidando um novo campo de trabalho expresso nos chamados departamentos de concepção de produtos das construtoras.

Caberá a esses departamentos de produto - e não mais ao arquiteto de escritório -, baseados em análises científicas de perfil de usuário e velocidade de vendas, a definição de soluções formais mais econômicas, do programa arquitetônico e o controle da interface da arquitetura com as demais engenharias - fato que destituirá o arquiteto da sua função de coordenador do canteiro de obras ${ }^{6}$.

Ocorre, assim, uma separação entre a dimensão estética, que ficará sob a responsabilidade dos escritórios de arquitetura, e a dimensão técnico-construtiva e mercadológica ${ }^{7}$, que ficará a cargo dos departamentos de produto das empresas construtoras. Essa nova racionalidade provocará também a racionalização e estandardização das soluções volumétricas ${ }^{8}$, contrastando com a tão aclamada criatividade da tradição local - fato ainda mais visível devido à excessiva densidade construtiva e à proliferação do edifício vertical na cidade do Recife neste período. 
Consolida-se, pois, uma nova divisão de trabalho, afetando não só os novos arquitetos assalariados das empresas de construção, mas o conjunto da profissão, pois desfaz-se a imagem do arquiteto como o único responsável pela concepção arquitetônica (RINGON,1997), pela coordenação dos projetos e do canteiro de obras, e, mesmo, devido à excessiva padronização dos programas do morar, sua imagem de profissional humanista criador de novas sociabilidades (MOULIN,1973).

É como se a arquitetura fosse definida por uma nova racionalidade científica atrelada à reprodução do status quo, e estivesse preocupada com a caracterização de um usuário padrão, comportamentos repetitivos e programas standards, quando antes, o pensamento arquitetônico, por estar situado no campo da arte e da inovação social, buscava o comportamento singular e inovador - se, assim, o profissional acreditasse que sua arquitetura pudesse contribuir para a mudança social!

No ensino, embora tenham ocorrido alguns movimentos em defesa de uma vinculação à realidade de mercado, prevalece a visão do arquiteto livre criador.

Ora, se essa recusa do campo do ensino em abarcar a nova racionalidade da arquitetura o coloca na sua tradicional função de pensar o futuro, em oposição ao atendimento às demandas práticas do presente, por outro lado, neste período, este debate ficará sob a responsabilidade exclusiva dos novos profissionais do mercado.

\section{A estética da elasticidade}

As transformações ocorridas no final do século $X X$ mostram uma importante transformação no ethos profissional do arquiteto, ao mesmo tempo em que se consolida um processo de urbanização baseado numa arquitetura vertical que fora, em certa medida, excessivamente racionalizada e estandardizada. A conjunção desses fatores com o impacto da verticalização e do adensamento construtivo na paisagem da cidade acabam por gerar um certo mal-estar entre os arquitetos, sobretudo quando o edifício vertical tornara-se a principal encomenda dirigida aos escritórios de arquitetura ${ }^{9}$.

Todavia, em meio a este mal-estar, e tentando contornar as limitações econômicas e técnicas impostas ao desenho do edifício, parece surgir um novo repertório estético visando transformar a maneira de conceber os volumes arquitetônicos.

Assim, se as reentrâncias e saques, na avaliação dos engenheiros, oneravam a obra e a expunha a sérias patologias (deformações nas estruturas, trincamentos de lajes, vazamentos, etc.), a solução encontrada pelos arquitetos para dar uma nova expressão aos volumes arquitetônicos parece ter sido a da busca da "elasticidade" das formas e volumes arquitetônicos.

Figura 5: Edifício Casa Alta, Av Boa Viagem, 2054, Boa Viagem, Recife-PE

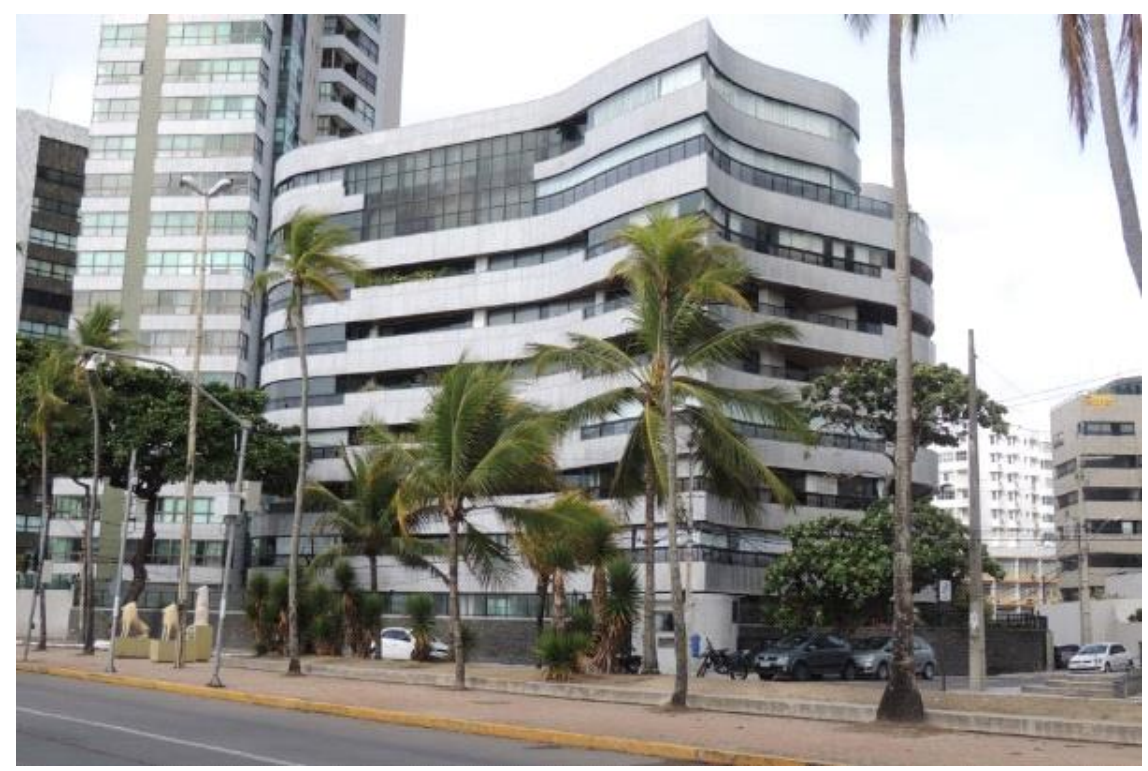

Fonte: Foto do autor 
De fato, foi através da elasticidade das formas dos tradicionais volumes prismáticos que os arquitetos deram aos edifícios uma nova expressão plástica, ao mesmo tempo em que mantiveram uma concepção construtiva racionalizada, pois baseada em vigas retilíneas (mesmo que levemente curvadas), diferentemente da solução estrutural fragmentada da arquitetura da estética da reentrância que tão bem caracterizou a primeira fase da arquitetura moderna recifense.

É a partir desse novo raciocínio compositivo e construtivo que surgem na paisagem urbana recifense, a partir sobretudo dos anos 90 , vários edifícios de formas elásticas, baseados em plantas elípticas, circulares, ou mesmo, de formas livres inspiradas na arquitetura de Oscar Niemeyer.

Figura 6: Edifício Zara, Av. Boa Viagem, 1478, Boa Viagem, Recife-PE

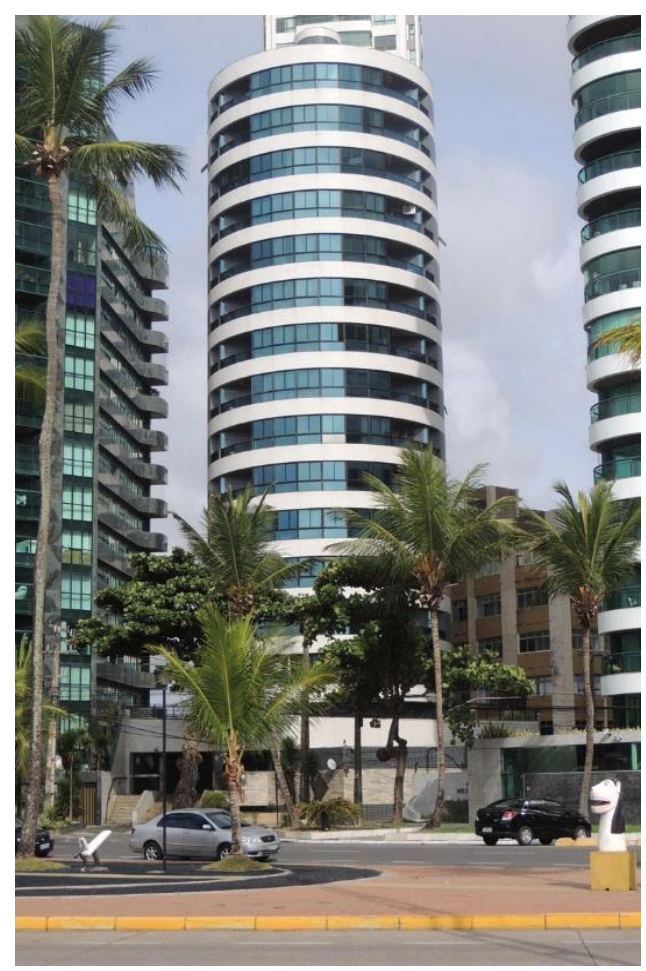

Fonte: Foto do autor

Todavia, deve-se apontar que essas novidades formais não respondem, unicamente, a um desejo de reconciliação entre a expressividade plástica e os imperativos técnicos e econômicos da construção (vigas retas, ausência de reentrâncias e saques), mas também buscam um melhor aproveitamento dos terrenos. Esse fato é ainda mais importante no momento que se observa uma acirrada concorrência entre as empresas construtoras e um significativo aumento no valor dos terrenos, fruto da progressiva escassez de terrenos urbanos e do acréscimo da densidade construtiva nas áreas mais privilegiadas da cidade.

Além disso, essas formas elásticas favorecem um significativo aumento na área de visada das fachadas e uma maior aproximação do edifício para com a rua (diminuição dos afastamentos), fatos que terminam por favorecer uma maior valorização econômica do imóvel, em especial, no caso da valorização das vistas para paisagens naturais, como é o caso da Praia de Boa Viagem, situado na zona sul da cidade ${ }^{10}$.

A partir dessas experiências inovadoras, fruto das experimentações dos próprios arquitetos de escritório, a legislação urbanística também vai se moldando no sentido de incorporar essas soluções formais ao conjunto das leis urbanas.

Assim, se a legislação dos primórdios da arquitetura recifense - característica da fase da estética da reentrância - favorecia o aparecimento de áreas de saque para além do limite estipulado pelos afastamentos (a exemplo das áreas dos guarda-roupas e jardineiras), a partir do início deste século, uma série de interpretações e instrumentos legais - sendo o mais importante o "afastamento em ponto médio" possibilitarão uma maior aproximação do edifício para com a rua - particularmente importante para edifícios verticais de grande altura - e, também, como dissemos, um maior aproveitamento das visadas das fachadas frontais para a paisagem, situação que, vale dizer, também favorece a valorização espacial dos ambientes 
internos dos apartamentos ${ }^{11}$.

Figura 7: Edifício João Heráclio, Av Boa Viagem, 342, Boa Viagem. Recife-PE

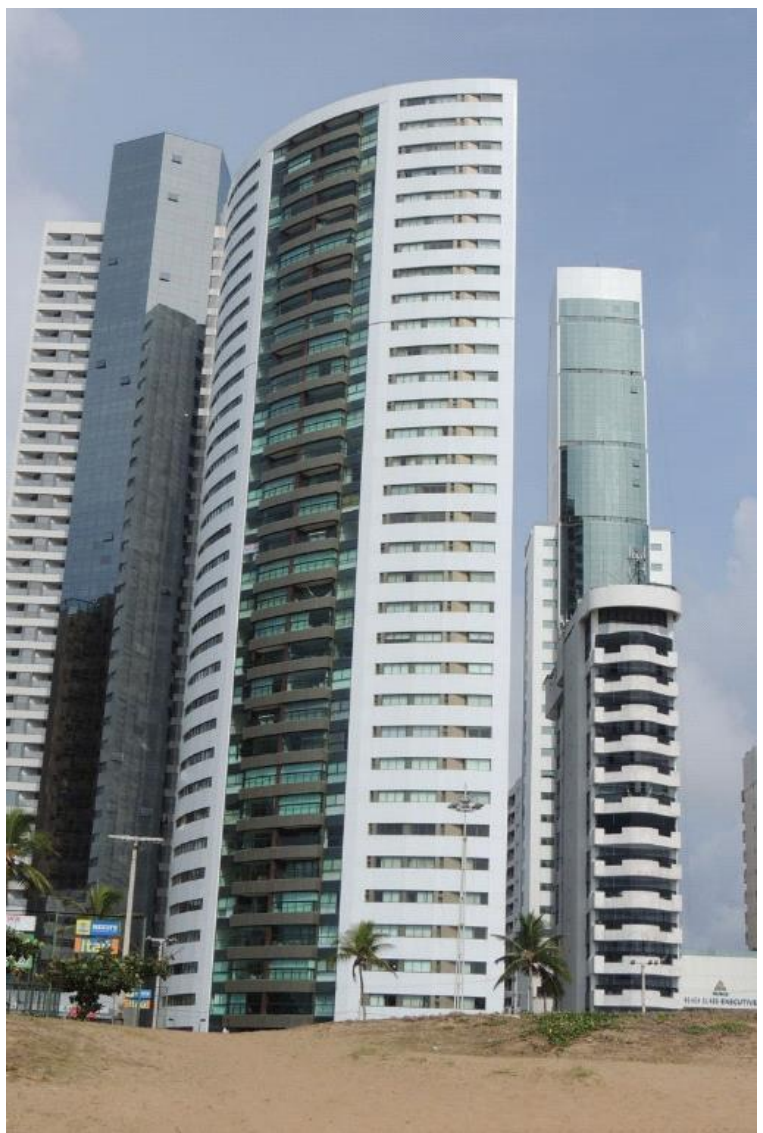

Fonte: Foto do autor

Figura 8: Nova interpretação de recuo (estética da elasticidade) baseado no ponto médio da fachada (segmento AB).

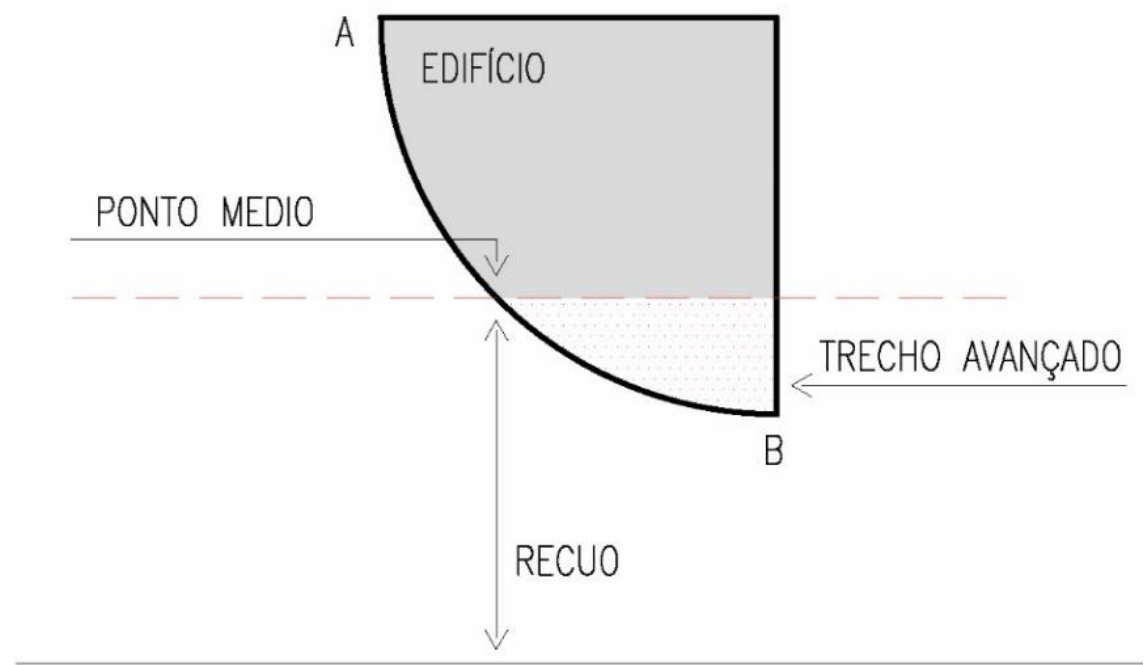

RUA 
Fonte: Desenho do autor

Figura 9: Recuo convencional para volumes prismáticos paralelos à rua

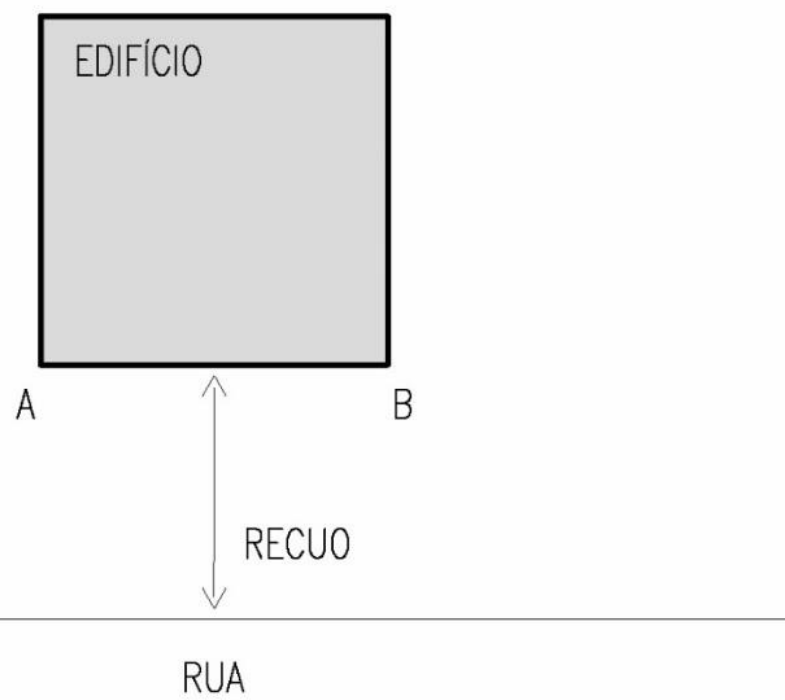

Fonte: Desenho do autor

Figura 10: Edf. Eng. Júlio Maranhão Filho, Av. Boa Viagem 998, Recife-PE 


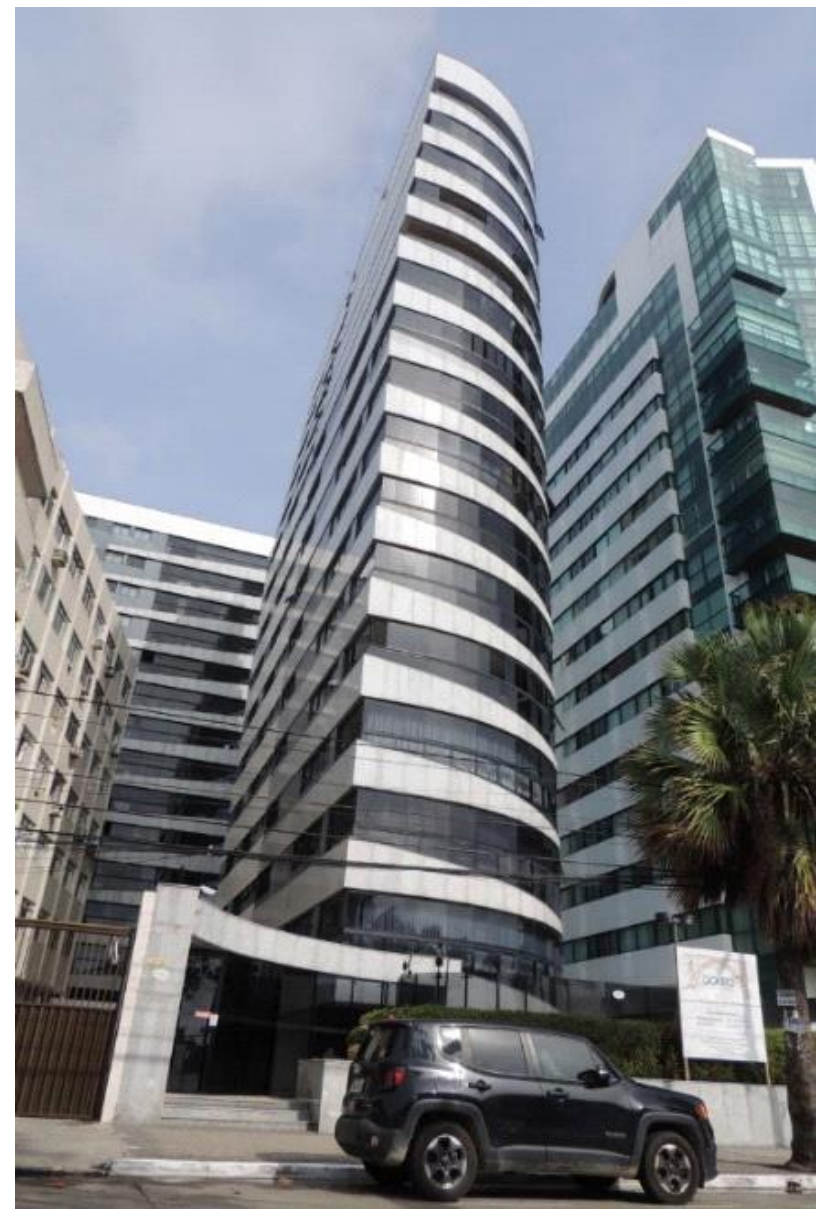

Fonte: Foto do autor

Figura 11: Edf. Villa Manguinhos, Av. Rua Cardeal Arcoverde, 85, Graças, Recife- PE

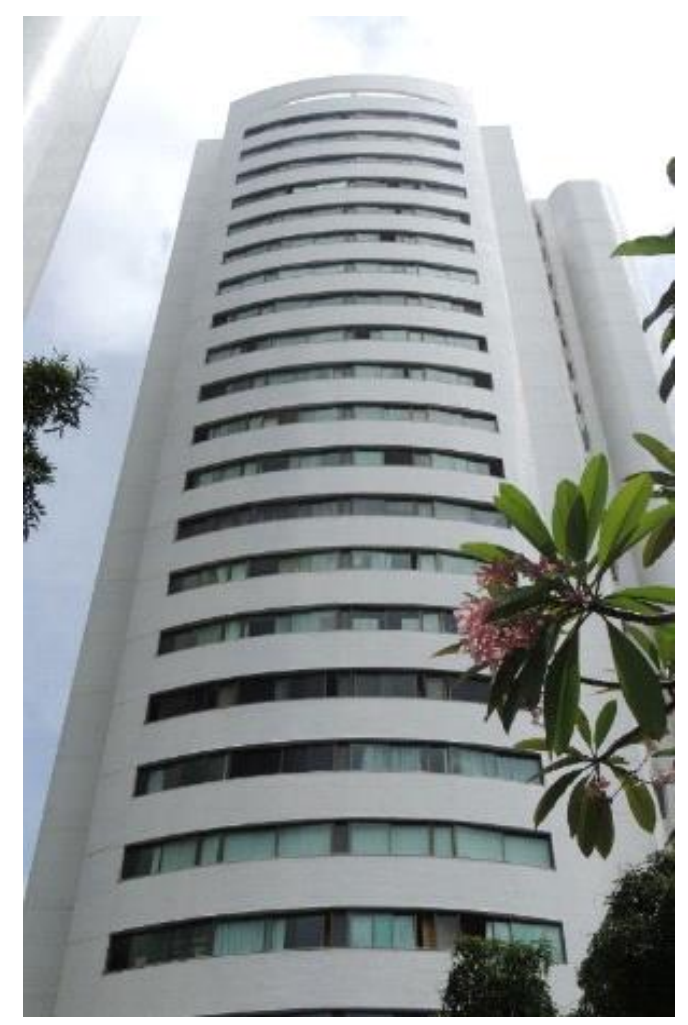

Fonte: Foto do autor 
Essas novas interpretações legais e a nova linguagem plástica dos edifícios saem das pranchetas dos arquitetos de escritório e, como dissemos, parece ter sido uma tentativa de reconciliação entre imperativos técnico-construtivos e mercadológicos e a busca de uma nova expressividade formal.

Não obstante essas tentativas de inovação, no início deste século, parece prevalecer entre os arquitetos, para além de uma crise de mercado de trabalho, o sentimento de uma certa crise de legitimidade. Este sentimento atinge não só os arquitetos, mas perpassa muito rapidamente todo o corpo social.

Prevalece o sentimento da perda de autonomia e liderança do arquiteto dentro do processo da concepção arquitetônica, sendo o mais visível a sua destituição do tradicional papel de coordenador do canteiro de obras - em que, durante todos os anos 60 e 70, deteve um papel de destaque na escolha das soluções técnicoconstrutivas. Contribui também a excessiva padronização e repetição do programa arquitetônico que parece ter transformado o arquiteto num mero repetidor de soluções cientificamente aprovadas por índices mercadológicos.

A coincidência dessas transformações com o forte crescimento e adensamento construtivo da cidade fundado numa arquitetura que também fora excessivamente racionalizada e estandardizada e que permanece como sendo a principal encomenda dos escritórios de arquitetura da cidade - desconstrói muito rapidamente a aura que sempre esteve associada à atividade do arquiteto de prancheta, ao mesmo tempo que transforma o edifício vertical - que outrora foi motivo de glória na arquitetura recifense - de herói em vilão!

Essa visão negativa do fazer arquitetônico e do modelo de urbanização da cidade perpassa muito rapidamente todo o corpo social, repercutindo no campo da gestão pública, movimentos da sociedade civil e até nas manifestações culturais como cinema e música!

Esse é o cenário em que, a partir de 2010, ocorre a reforma curricular do Curso de Arquitetura da UFPE ${ }^{12}$, no interior da qual a metodologia de pensar o edifício ocorre no interior de um atelier integrado de projeto reunindo as matérias de projeto, urbanismo e paisagismo - e onde a palavra de ordem parece ser a da busca por uma arquitetura dita contextualizada.

Assim, pode-se dizer, embora ainda seja cedo para mostrar exemplos e obras realizadas, que o pensamento arquitetônico neste início de século, migra do edifício para a cidade.

\section{CONSIDERAÇÕES FINAIS}

Analisando as fases da arquitetura vertical do Recife, percebemos a passagem de um repertório arquitetônico baseado nas reentrâncias e saliências - característico da fase áurea do modernismo local - para um período de forte restrição no repertório estético, que, por repetir formas anteriores através de grafismos, chamamos de estética da "fantasmagoria". Este período da arquitetura também se caracteriza por uma transformação importante no papel do arquiteto dentro do processo de concepção e execução da obra, fato que desconstrói importantes representações do arquiteto enquanto livre criador e artífice de novas sociabilidades.

Passado esse período de grande simplificação estética, encontramos uma nova fase de renovação estética, em que se buscou conciliar as restrições técnicas e econômicas - diagnosticadas pelas empresas da construção - com a busca de uma nova expressividade formal, recorrendo, para isso, ao uso de formas elásticas.

Todavia, se a estética da elasticidade concedeu aos arquitetos a oportunidade de contornar as críticas à excessiva estandardização e simplificação da arquitetura, ela ocorreu num momento em que a sociedade e a academia elaboraram uma forte crítica ao modelo urbanístico baseado no edifício vertical. Assim foi que a academia passou a criticar o estudo do edifício vertical isolado do contexto urbano, priorizando uma reflexão centrada na valorização da paisagem da cidade. É por esse caminho que surge na atual cultura arquitetônica uma demanda por uma arquitetura dita contextualizada.

Resta saber como os arquitetos vão conciliar essa arquitetura de traços mais delgados e elásticos - mais favorável, portanto, a uma estratégia de "choque" ou "destaque" para com o contexto urbano local - com essa nova demanda de diálogo com a cidade existente. Da mesma forma, é preciso verificar como a academia principal ator no questionamento do atual modelo arquitetônico e urbanístico da cidade do Recife - conciliará sua crítica a favor de uma "arquitetura urbana" com sua recorrente hesitação em estudar - mesmo que visando sua reconceitualização - o projeto do edifício vertical construído em lote isolado, que ainda representa a principal encomenda dos escritórios de arquitetura!

De qualquer forma, e ao que parece, este apelo a volta à "cidade" parece claro não só no campo da academia e nos atuais debates por uma nova legislação arquitetônica e urbanística, mas também já se percebe embora se trate, ainda, de um movimento incipiente no mundo da prática profissional - na maior sensibilidade 
dos novos projetos de arquitetura em se adaptar ao contexto e buscar uma maior valorização da vida urbana.

Isto posto, será, então que, de fato, a segunda década do século XXI poderá anunciar uma nova fase na arquitetura recifense, e assim poderemos falar de uma estética da arquitetura urbana ou estética da cidade?

Com a palavras os arquitetos - professores e práticos - mas, sobretudo, a nova geração atualmente em formação sob a atmosfera do debate de retorno à cidade!

\section{REFERÊNCIAS}

LAPROVITERA DA MOTTA, Enio - L'Architecte et le peuple à Recife (Brésil), 1959-2009. Tese de Doutorado. Paris: École des Hautes Études em Sciences Sociales. 2009.

MOULIN, Raymonde - Les architectes. Métamorphose d'une profession libérale. Paris: Calmann-Lévy, 1973.

NASLAVSKY, Guilah - Arquitetura moderna no Recife. 1949-1972. Recife: Ed. Edileuza Da Rocha, 2012.

RINGON, Gérard - Histoire du Métier d’Architecte en France. Paris: Presses Universitaires de France - PUF, 1997.

\section{NOTAS}

1 Para uma história da arquitetura moderna no Recife entre 1949 e 1972, consultar NASLAVSKY (2012).

${ }^{2} \mathrm{O}$ curso de arquitetura funcionou no interior da Escola de Belas Artes de Pernambuco até o ano de 1959 quando se funda a Faculdade de Arquitetura da Universidade do Recife (hoje UFPE). A reforma curricular de 1963 é, portanto, a primeira revisão pedagógica da faculdade independente.

${ }^{3}$ Para uma história do ensino de arquitetura de 1959 a 2009, consultar LAPROVITERA DA MOTTA (2009).

${ }^{4}$ Usamos o termo "fantasmagoria" por se tratar de um conceito usado no campo da estética. Na verdade, seu significado se aproxima, em certa medida, dos conceitos de "alegoria" ou "simulacro" - ambos do campo da estética - e indicam situações onde um determinado objeto cita um outro objeto ou fenômeno sem ter a pretensão de reproduzi-los na íntegra.

${ }^{5}$ O Código de Defesa do Consumidor é instituído em 1990 e passa a vigorar a partir de março de 1991. Por isso mesmo, a partir sobretudo do início dos anos 90 , a construção civil - em especial, a residencial - será objeto de várias ações jurídicas de contestação de usuários alegando os mais diversos problemas técnicos de construção nos edifícios.

${ }^{6} \mathrm{Na}$ verdade, no início, este trabalho de racionalização foi feito por consultores autônomos - em geral, engenheiros saídos dos quadros da construtora ENCOL - contratados pelas construtoras para assessorar o arquiteto autor do projeto. Aos poucos, os chamados "consultores de projeto" tornam-se funcionários das construtoras, e, num terceiro momento, já com a criação dos chamados departamentos de produtos das construtoras, essa atividade de "racionalização" e "compatibilização" será feita por arquitetos, a partir de então, tornados assalariados das empresas de construção.

${ }^{7} \mathrm{O}$ ato de projetar passará, então, a obedecer a uma série de índices científicos de aproveitamento. A definição do programa arquitetônico e respectiva área de construção, se baseia, a partir de então, em análises de velocidade de vendas e das preferências dos usuários. $\mathrm{A}$ definição do "traçado" da planta baixa da lâmina e dos apartamentos também será objeto de análises baseadas em índices matemáticos, sendo os mais usuais: a) o índice de compacidade (relação do perímetro de fachada com a área total da lâmina); b) relação da área total privativa com a área total de uso comum; c) relação da área seca (sala, quartos, etc) com a área molhada dos apartamentos (wcs e cozinha); d) relação da área total privativa do apartamento com a área ocupada por paredes divisórias; dentre outros.

${ }^{8}$ Vale ressaltar que o debate e diagnóstico da falta de "racionalidade" ou "problemas" dos edifícios - ou, para usar um termo mais preciso que, embora recorrente no campo da engenharia, só então passa a aparecer no campo do projeto de arquitetura, as "patologias" do edifício - aparecem nos relatórios do campo da engenharia sem que sejam contestados empiricamente pelos arquitetos. As patologias mais relatadas dizem respeito aos vazamentos resultantes de trincamento de lajes e revestimentos - daí o combate ao excesso de balanços e reentrâncias - ou, simplesmente, devido ao uso indiscriminado de jardineiras e lajes impermeabilizadas. A comprovação científica - ou contra-argumento - de que estas patologias resultaram de falta de manutenção e não da solução arquitetônica em si, é ainda uma peça em aberto na história da nossa profissão. Ora, diante do silêncio do campo da arquitetura e frente as contestações do emergente movimento de defesa do consumidor a solução imediata e inevitável foi a "racionalização" e "estandardização" da construção e da arquitetura.

${ }^{9} \mathrm{O}$ mal-estar pode ser creditado, por um lado, à percepção crítica que a sociedade - e, também os próprios arquitetos, embora estes possam por autodefesa tentar naturalizar as mudanças - fez do crescente distanciamento da prática de arquitetura para com as decisões em matéria das opções técnico-construtivas e na elaboração e definição dos programas arquitetônicos. Por outro lado, também no campo da estética, a excessiva racionalização das soluções arquitetônicas contrasta com a criatividade da fase inaugural da arquitetura e fragiliza a imagem do arquiteto livre criador de formas. Some-se a isso, o fato do edifício vertical passar a ser a principal encomenda dos escritórios de arquitetura e impactar de forma nunca vista na paisagem urbana da cidade do Recife.

${ }^{10}$ Ver figura 8 e 9, em que se faz um comparativo entre o afastamento tradicional baseado num edifício prismático ortogonal à rua (Fig.9) e a nova interpretação de recuo para volumes da estética da elasticidade (Fig. 8), em que o afastamento é medido para o ponto médio da fachada (segmento AB). Observar também, nesses desenhos, como a elasticidade gera uma área de saque aproximando o edifício da rua, além de ampliar a área de fachada (segmento $A B$ ), aumentando assim as visadas para o exterior do edifício, ou seja, para a 
paisagem urbana ou natural.

11 ver nota 10 e Fig. 8.

${ }^{12}$ A partir da reforma pedagógica de 2010 do Curso de Arquitetura da UFPE, as antigas disciplinas denominadas de Plástica 1 e Plástica 2, criadas em 1963, são definitivamente extintas, e o exercício de pensar o edifício vertical, pelo menos ao nível do ensino, parece passar por uma nova transformação.

NOTA DO EDITOR (*) O conteúdo do artigo e as imagens nele publicadas são de responsabilidade do(s) autor(es). 